IBIMA Publishing

Journal of Research in Obesity

http://www.ibimapublishing.com/journals/OBES/obes.html

Vol. 2014 (2014), Article ID 558641, 10 pages

DOI: $10.5171 / 2014.558641$

Research Article

\title{
Accuracy of the Weight-for-age Index in Identifying Obese Children in the Emergency Setting
}

\author{
Reetika Tripathi ${ }^{1}$, QuynhDoan ${ }^{2}$, Vikram Sabhaney ${ }^{2}$ and Kathy Boutis ${ }^{3}$ \\ ${ }^{1}$ University of Toronto, University Avenue, Toronto \\ ${ }^{2}$ Department of Pediatrics, University of British Columbia, Division of Emergency Medicine, \\ Vancouver BC \\ ${ }^{3}$ Division of Emergency Medicine, Department of Pediatrics, the Hospital for Sick Children and the \\ University of Toronto; University Avenue, Toronto
}

Correspondence should be addressed to: Kathy Boutis; kleanthi.boutis@sickkids.ca

Received Date: 15 December 2013; Accepted Date: 6 February 2014; Published Date: 30 April 2014

Academic Editor: Giorgio Bedogni

Copyright (C 2014 Reetika Tripathi, QuynhDoan, Vikram Sabhaney and Kathy Boutis. Distributed under Creative Commons CC-BY 3.0

\begin{abstract}
Obesity has been defined as weight-for-age $\geq 95^{\text {th }}$ percentile for research/clinical settings like the emergency department where height is not routinely available. Our main objective was to determine the sensitivity of weight-for-age $\geq 95 \%$ th percentile in identifying obesity, using Body Mass Index (BMI)-for-age $\geq 95 \%$ percentile as the reference standard. We also determined the specificity, and predictive values, and the correlation between weight and BMI-for-age values.

This was a cross-sectional study with prospectively collected data conducted at two urban, tertiary care pediatric emergency departments in Canada. Children between 2 and 17 years of age with acute extremity injuries were enrolled.

Of the 2259 participants, 1283 (56.1\%) were male and the mean (SD) age was 9.5 (4.1) years. Using weight-for-age $\geq 95^{\text {th }}$ percentile, $326[14.3 \%(12.9,15.7])$ were classified as obese, while using BMI-for-age $\geq 95^{\text {th }}$ percentile criteria determined that $363[16.1 \%(14.6,17.7)]$ were obese, $\mathrm{p}<0.0001$. The sensitivity $(95 \% \mathrm{CI})$ of weight-for-age $\geq 95^{\text {th }}$ percentile to identify obesity was $62.2 \%(57.0,67.2)$. The specificity, positive and negative predictive values were $94.5 \%(93.6,95.6), 14.4 \%(13.0,16.0)$, and $85.6 \%(84.0,87.0)$, respectively. The correlation between BMI and weight-for-age was $0.71(0.68,0.73)$.

Although there may be limited validity in using this weight-for-age cut-off as a definition for obesity in research that includes children with acute injuries, the high specificity may provide some clinical utility in identifying two-thirds of children who are obese while minimizing false labeling of this condition.
\end{abstract}

Keywords: Obesity, Pediatrics, Definition.

Cite this Article as: Reetika Tripathi, QuynhDoan, Vikram Sabhaney and Kathy Boutis (2014), "Accuracy of the Weight-for-age Index in Identifying Obese Children in the Emergency Setting," Journal of Research in Obesity, Vol. 2014 (2014), Article ID 558641, DOI: 10.5171/2014.558641 


\section{Introduction}

Pediatric obesity is characterized by the World Health Organization as one of the most serious public health challenges of the 21st century. (Formiguera and Canton, 2004) In 2010, an estimated 43 million preschool children world-wide were identified as overweight or obese, representing a 60\% increase since 1990 . (de Onis et al., 2010) Within North America rates of obesity have steadily increased, and in the Canada between 2009-2011, $31.5 \%$ of children were classified as overweight $(19.9 \%)$ or obese (11.7\%). (Ogden et al., 2012, Tremblay and Willms, 2000, Roberts KC et al., 2012) Children who are obese are at risk of many acute and chronic medical complications and require more medical care, (Daniels, 2006) including frequent use of the emergency department. (Estabrooks and Shetterly, 2007, Prendergast et al., 2011)

Research and public health initiatives that examine the relationship between body habitus and a specific medical condition often uses the definition of Body Mass Index $(\mathrm{BMI})>95$ th percentile to define obesity. (Kuczmarski RJ et al., 2002) However, height is not routinely recorded in acute care clinical settings like the emergency department, and therefore weight-for-age $>95$ th percentile as a cutoff for defining obesity has been used in these situations. (Backstrom et al., 2012a, Leet et al., 2005a, Pomerantz et al., 2010a, Whitaker and Orzol, 2006) As such, research examining the association between weight and common urgent complaints like injuries often uses the weight-for-age $>95$ th percentile metric to define obesity. (Backstrom et al., 2012b, Leet et al., 2005b, Pomerantz et al., 2010b, Ryan et al., 2010) Yet, there is currently limited evidence demonstrating how accurate the weight-for-age > 95th percentile is in identifying obesity. One study by Stettler et al used national data from the United States and determined that weight-for-age $>95$ th percentile was $82 \%$ sensitive in the detection of obesity relative to the BMI > 95th percentile definition. (Stettler et al., 2007) But, validating this sensitivity in children with injuries that present to the acute care setting is currently lacking.

Our main objective was to determine the accuracy of weight-for-age $\geq 95^{\text {th }}$ percentile in identifying the obese children who presented to the emergency department with an extremity injury relative to the BMI $\geq 95$ th percentile reference standard. We also examined the correlation of weightfor-age and BMI-for-age, and the distribution of differences between the weight-for-age and BMI-for-age percentiles.

\section{Methods}

\section{Study Design and Setting}

This was a cross-sectional study with prospectively collected data conducted at two urban, tertiary care pediatric emergency departments in Canada.

\section{Study Setting and Population}

Eligible children were between the ages of two and 17 years and presented to the emergency department between June 1, 2011 and December 31st, 2012 with a nonpenetrating injury to an extremity. We selected extremity injuries since they one of the most common pediatric presenting complaints to emergency departments and affect all ethnic and socioeconomic backgrounds. (Pomerantz et al., 2010b) We excluded families who could not speak English, children with brittle or fragile bones, pre-existing neuromuscular disorder, global developmental delay and children with poly-trauma. The research ethics review boards of both institutions approved the study.

\section{Definitions}

Children were classified as obese in accordance with weight if they were at or above the 95th percentile for weight-forage and gender based on data from Centers for Disease Control. (Kuczmarski RJ et al., 2002, Ogden CL and Flegal KM, 2010) Using the BMI standard, children with a BMI-forage at or above the 95th percentile were labelled as "obese." (Kuczmarski RJ et al., 
2002, Ogden CL and Flegal KM, 2010) The weight-for-age and BMI-for-age percentiles are based on the Centre for Disease Control growth charts, (Kuczmarski RJ et al., 2002) which are based on children and adolescents who participated in national studies conducted between 1963 and 1994.

\section{Patient Recruitment}

At Site 1, patients were enrolled by on-site trained research assistants, who provided 15-hour daily research presence in the emergency department. At Site 2, there was intermittent coverage by research assistants whereby research assistants provided coverage on average from 1000 to 2200 daily.

At both hospitals, following triage, potential study participants were identified by monitoring the site-specific emergency department tracking system for appropriate complaints/triage histories that suggested the presence of an extremity injury. Research assistants then approached families to screen for eligibility. If eligible, research assistants obtained informed consent and any applicable assent. A record of those not enrolled was kept to assess for enrollment bias. On a study form, we recorded age calculated using date of birth (day/month/year) and date of presentation (day/month/year), sex, height measured in centimeters from the top of the head to the heel of the patient, and weight measured in kilograms using a hospital standard scale. Height was measured using a wall stadiometer in ambulating patients, and in those who were non-ambulatory height was measured using a measuring tape while lying straight on the examination bed.

\section{Study Outcomes}

The primary outcome was obesity (yes/no) as detected by BMI-for-age and the predictor is obesity (yes/no) as detected by weight-for-age. Weight-for-age and BMIfor-age percentiles were calculated using standardized methods (http://www.cdc.gov/nccdphp/dnpa/grow thcharts/training/modules/module1/text/ intro.htm) and double checked for accuracy tools available from Baylor College of Medicine and USDA/ARS Children's Nutrition Research Center, Houston (http://www.bcm.edu/bodycomplab/Flash apps/bmiVAgeChartpage.htm) and the British Columbia Children's Hospital Endocrinology and Diabetes Unit, Vancouver

(http://www.bcchildrens.ca/Services/Spec ializedPediatrics/EndocrinologyDiabetesU nit/ForProfessionals/AnthropometricCalcu lators.htm). Secondary outcomes included a) the specificity, positive and negative predictive values of weight-for-age $\geq 95^{\text {th }}$ percentile; b) the diagnostic accuracy of the $3^{\text {rd }}, 5^{\text {th }}, 10^{\text {th }}, 20^{\text {th }}, 50^{\text {th }}, 90^{\text {th }}, 97^{\text {th }}$ percentile weight-for-age values; c) the predictive value of patient demographic variables (age as a continuous variable and categorized in three relatively physiologically similar age groups of 2-5, 6$11, \quad 12-17$ years; sex) in accurately identifying obesity using weight-for-age $\geq$ 95th percentile relative to the BMI standard; d) the correlation of weight-forage and BMI-for-age values; and e) the proportion of patients where weight-forage was consistent with the BMI-for-age percentiles within a specific range of percentage points.

\section{Sample Size Considerations}

This study was powered for the primary outcome, the sensitivity of the weight-forage $>$ 95th percentile to identify obesity compared to BMI. Based on previous data from a similar population, we expect the prevalence of obesity to be $11 \%$ of our patient sample. (Campbell et al., 2013) Assuming the weight for age percentile method is at least $80 \%$ sensitive, (Stettler et al., 2007) in order to achieve +/- 5\% precision with $95 \%$ confidence on the sensitivity, the estimated required sample size was 2235 subjects.

\section{Statistical Analyses}

Descriptive analyses were used to describe demographics. Proportions were reported with respective 95\% confidence intervals. Logistic regression was used determine if there was any significant associations 
between the binary outcome (accurate/not accurate) weight-for-age $\geq 95$ th percentile and the aforementioned patient demographic variables. Odds of the outcome for a given variable were reported with respective 95\% confidence intervals. Goodness-of-fit of final model to the data was tested using the Hosmer-Lemeshow test ( $p>0.05$ rejects the null hypothesis of poor fit). A receiver operator curve was plotted to check the predictive ability of the model to predict on the binary outcome of interest (accuracy of weight-for-age $\geq 95$ percentile to define obesity as per BMI-forage - i.e. proportion "accurate"). We reported the area under the receiver operator curve with respective 95\% confidence interval. Pearson's correlation co-efficient was used to determine the correlation of weight-for-age and BMI-forage. Finally, we described the distribution

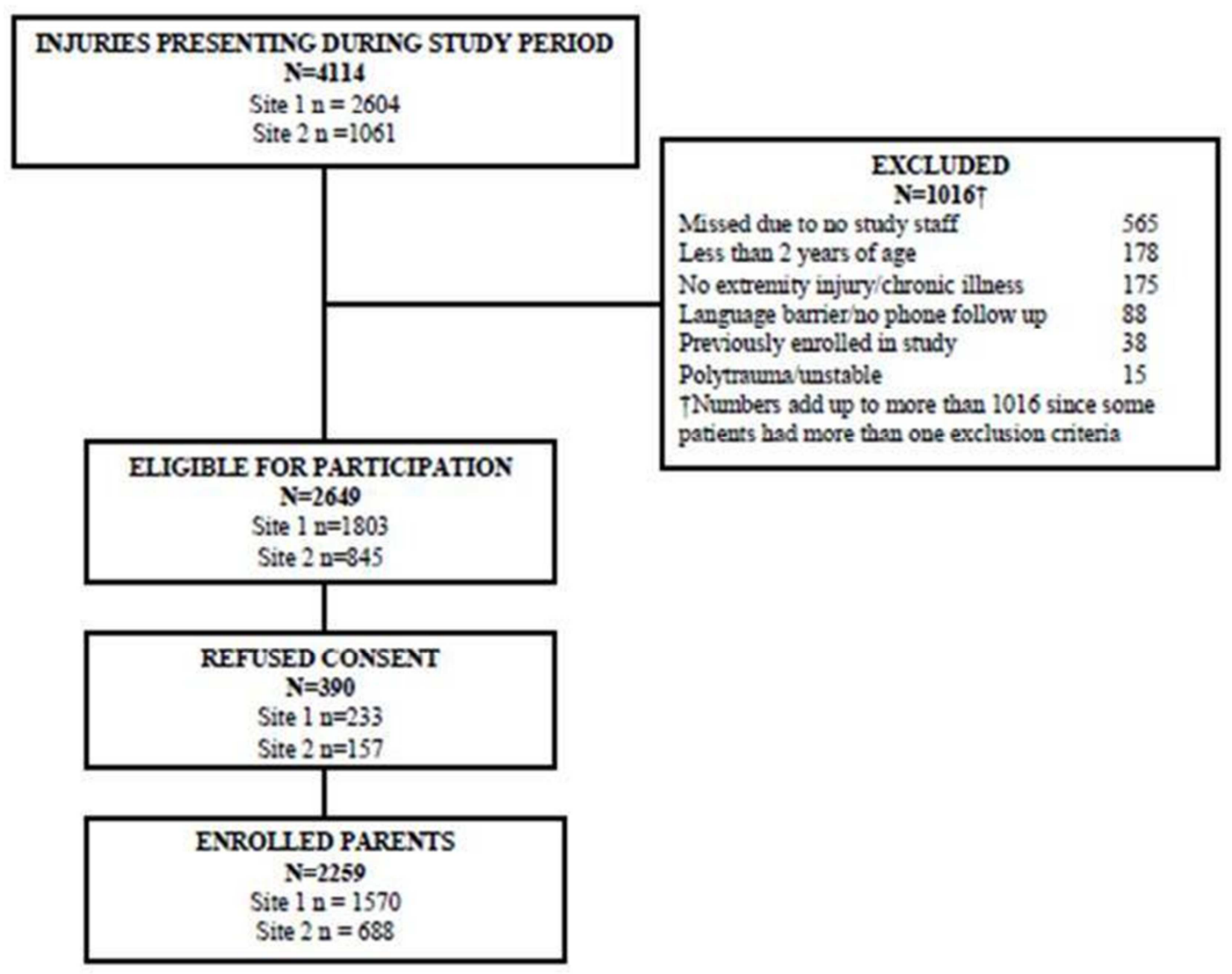

of differences in weight-for-age and BMIfor-age percentiles, and calculated crossclassification of categories of weight-forage and BMI-for-age percentiles. All analyses were performed using SAS statistical software (version 9.2; SAS Institute Inc, Cary, NC).

\section{Results}

Data from 2259 children were available for analysis (Figure 1). Of these, 1283 (56.1\%) were male and the mean (SD) age was 9.5 (4.1) years. The mean (SD) height and weight were 38.2 (20.3) kg and 137 (27.4) $\mathrm{cm}$, respectively. Using BMI-for-age criteria for obesity, $16.1 \%$ [95\% CI 14.7 - 17.7] were classified as obese, while using the weight-for-age $14.3 \%$ [95\% CI 13.0 - 15.9] were classified as obese, $\mathrm{p}<0.0001$ (Table 1).

Figure 1: Patient Enrolment 
Table 1. Number of Subjects and Prevalence of Obesity Status by Sex and Age Groups

\begin{tabular}{|c|c|c|c|c|c|c|}
\hline & \multicolumn{2}{|c|}{$\begin{array}{l}\text { Number of } \\
\text { Study Children }\end{array}$} & \multicolumn{2}{|c|}{$\begin{array}{l}\text { Prevalence of Obesity } \\
\text { as per BMI-for-age } \geq \quad 5^{\text {th }} \\
\text { percentile, no. }(\% ; 95 \% \mathrm{CI})\end{array}$} & \multicolumn{2}{|c|}{$\begin{array}{l}\text { Prevalence of Obesity } \\
\text { as per weight-for-age } \geq 95^{\text {th }} \\
\text { percentile, no. }(\% ; 95 \% \mathrm{CI})\end{array}$} \\
\hline & $\begin{array}{l}\text { Mal } \\
\mathrm{e}\end{array}$ & Female & Male & Female & Male & Female \\
\hline All & $\begin{array}{l}128 \\
3 \\
\end{array}$ & 976 & $\begin{array}{l}225(10.0 ; 8.8- \\
11.2)\end{array}$ & $\begin{array}{l}138 \quad(6.1 ; 5.1- \\
7.1)\end{array}$ & $\begin{array}{l}212(9.4 ; 8.2- \\
10.6)\end{array}$ & $\begin{array}{l}114(5.0 ; 4.1- \\
5.9)\end{array}$ \\
\hline $\begin{array}{l}2-5 \\
\text { years } \\
\end{array}$ & 183 & 187 & $\begin{array}{l}2(11.3 ; 8.1- \\
14.5)\end{array}$ & $\begin{array}{l}38(10.2 ; 7.1- \\
13.3)\end{array}$ & $\begin{array}{l}33(8.9 ; 6.0- \\
11.8)\end{array}$ & $\begin{array}{l}31(8.4 ; 5.6- \\
11.2)\end{array}$ \\
\hline $\begin{array}{l}6-11 \\
\text { years }\end{array}$ & 507 & 423 & $\begin{array}{l}86(9.2 ; 7.3- \\
11.1)\end{array}$ & $\begin{array}{l}63(6.8 ; 5.2 \quad- \\
8.4)\end{array}$ & $\begin{array}{l}80(8.6 ; 6.8- \\
10.4)\end{array}$ & $\begin{array}{l}44(4.7 ; 3.3- \\
6.1)\end{array}$ \\
\hline $\begin{array}{l}12-17 \\
\text { years }\end{array}$ & 593 & 366 & $\begin{array}{l}97(10.1 ; 8.2- \\
12.0)\end{array}$ & $\begin{array}{llll}37 & (3.9 ; & 2.7 & - \\
5.1) & & & \\
\end{array}$ & $\begin{array}{l}99(10.3 ; 8.4- \\
12.2)\end{array}$ & $\begin{array}{l}39(4.1 ; 2.9- \\
5.4)\end{array}$ \\
\hline Total & \multicolumn{2}{|l|}{2259} & \multicolumn{2}{|c|}{$363(16.2 ; 14.7-17.7)$} & \multicolumn{2}{|c|}{$326(14.4 ; 13.0-15.9)$} \\
\hline
\end{tabular}

The sensitivity of weight-for-age $\geq 95$ th percentile to identify obese children (primary outcome) was $62.2 \%$ [95\% CI 57.2-67.2] (Table 2). The specificity, positive and negative predictive values for this weight-for-age cut-off were $94.7 \%$ [95\% CI 93.7-95.7], 69.3\% [95\% CI 64.374.3], and $92.9 \%$ [95\% CI 91.7-94.0], respectively. There was a statistically significant trend of decreasing sensitivity for increasing weight-for-age percentile $(\mathrm{p}<0.001)$, with the highest sensitivity of weight-for-age $\leq 3 \%$ at $96.1 \%[95 \% \mathrm{CI}$ 94.1-98.1] and the lowest at 51.7\% [95\% CI 46.6-56.9] for weight-for-age $\geq 97$ th percentile. 
Table 2. For Each Weight-For-Age Percentile Cut-Off Point, Prevalence of Subjects at or above the Cut-Off, Sensitivity, Specificity, PPV and NPV, with 95\% CI's, for Obese (BMI at or above the 95 $^{\text {th }}$ Percentile) Status in a Sample of Pediatric Patients Presenting to the Emergency Department

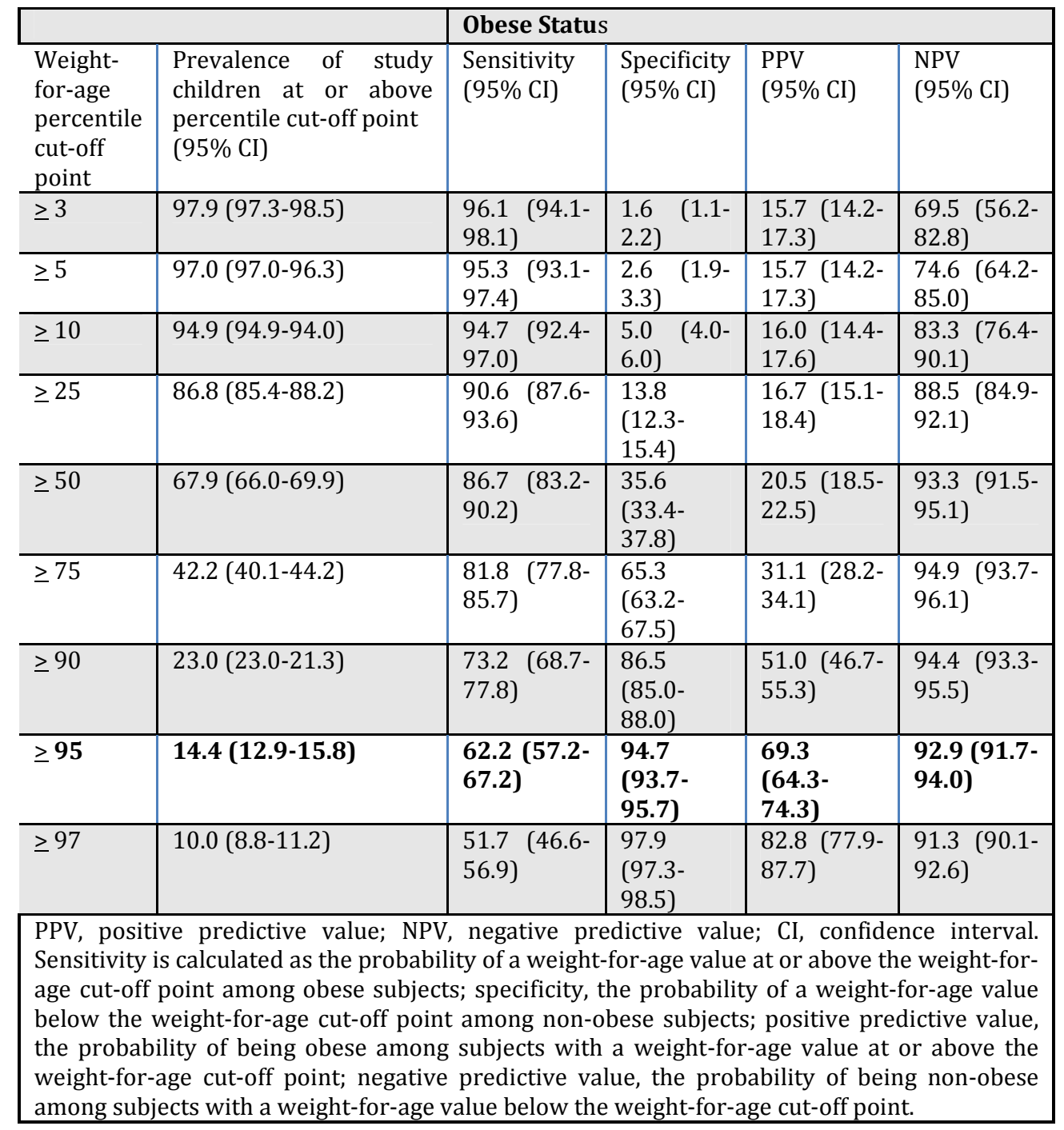

Weight-for-age $\geq 95$ th percentile did not have a higher odds of being accurate in children 6-11 versus 2-5 years [OR=0.87; $95 \%$ CI $0.48,1.56]$, those $12-17$ versus $2-5$ years $[\mathrm{OR}=0.61 ; 95 \%$ CI $0.35,1.08]$, or female versus male sex [OR=1.14; $95 \% \mathrm{CI}$ 0.86, 1.49)] (Hosmer-Lemeshow $\mathrm{p}=0.91$ (rejecting the null hypothesis that; Predictive ability of the logistic regression model, area under the curve $=0.55 ; 95 \% \mathrm{CI}$ $0.52,0.59$ ).

In $80 \%$ of cases, the difference between the weight-for-age and BMI-for-age percentiles was less than $5 \%$. The BMI-for-age and weight-for-age percentiles agreed to within 0 to 2.5 percentage points for $50.3 \%$ of children. In the remaining cases, $31.9 \%$ had weight-for-age percentiles >2.5 percentage points higher than their BMIfor-age percentiles, while $17.7 \%$ had weight-for-age percentiles $>2.5$ percentage points lower than their BMI- for-age percentiles (Figure 2). The Pearson's correlation between the BMI-for-age and weight-for-age was 0.71 . 


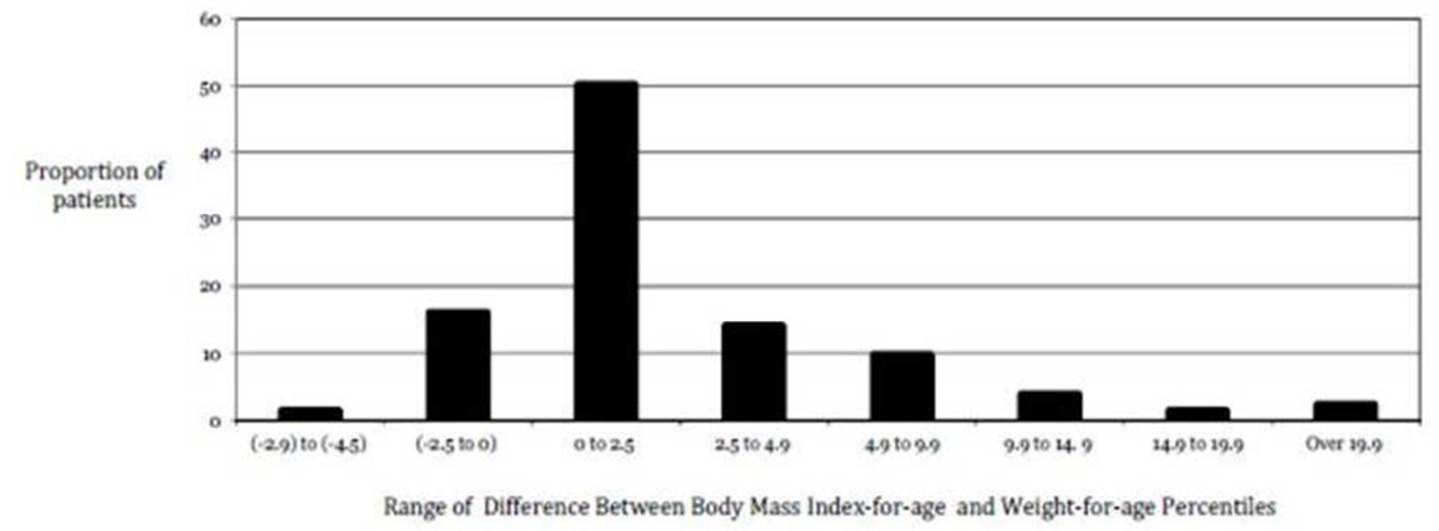

Figure 2. Proportion of Patients Weight-For-Age Percentiles that Were Consistent with Body Mass Index-For-Age by a Specified Range

While $69.3 \%$ of children met criteria for obesity ( $\geq 95$ th percentile) using weightfor-age and BMI-for-age criteria, an additional $28.4 \%$ of those who were classified as obese per weight-for-age would have still been classified as overweight (i.e. $\geq 85$ th percentile) by BMIfor-age criteria (Table 3). Further, of the 1593 cases classified as weight-for-age $\leq$ 84.9th percentile, 1410 (88.5\%) were similarly classified by the BMI-for-age. Nevertheless, 136/362 (37.6\%) who met criteria for BMI-for-age defined obesity were classified as non-obese by the weightfor-age metric, including $13 \%$ who were reported at $\leq 50$ th weight for age percentile, accounting for the compromised sensitivity of weight-for-age.

Table 3. Cross-Classification of Categories of Weight-For-Age and Body Mass Index-ForAge Percentiles

\begin{tabular}{|c|c|c|c|c|c|}
\hline & Body Mass & dex-for-ag & rcentile & & \\
\hline $\begin{array}{l}\text { Weight-for-age } \\
\text { percentile }\end{array}$ & $\begin{array}{l}\geq 95 \\
N=362\end{array}$ & $\begin{array}{l}90-94.5 \\
N=168\end{array}$ & $\begin{array}{l}85-89.9 \\
N=146\end{array}$ & $\begin{array}{l}50-84.9 \\
N=781\end{array}$ & $\begin{array}{l}\leq 50 \\
N=797\end{array}$ \\
\hline$\geq 95$, no. $(\%)$ & $226(62.4)$ & $56(33.3)$ & $25(17.1)$ & $16(2.0)$ & $3(0.3)$ \\
\hline 90 - 94.9, no. (\%) & $40(11.0)$ & $45(26.8)$ & $42(28.8)$ & $62(7.9)$ & $5(0.6)$ \\
\hline 85 - 89.9, no. (\%) & $21(5.8)$ & $16(9.5)$ & $22(15.1)$ & $71(9.1)$ & $11(1.4)$ \\
\hline 50 - 84.9, no. (\%) & $28(7.7)$ & $46(27.4)$ & $51(34.9)$ & $489(62.6)$ & $257(32.2)$ \\
\hline$\leq 50$ th, no. $(\%)$ & $47(13.0)$ & $5(3.0)$ & $6(4.1)$ & $143(18.3)$ & $521(65.3)$ \\
\hline
\end{tabular}

\section{Discussion}

In children who presented to an emergency department with an extremity injury, we demonstrated that the weight-for-age $\geq$ $95^{\text {th }}$ percentile had a sensitivity of $62 \%$ and a specificity of $95 \%$ in diagnosing obesity relative to the BMI reference standard. Alternatively, the correlation between the weight-for-age versus BMI-for-age definition for obesity was very good and the majority of children had BMI-for-age and weight-for-age values that were within five percentage points.
The sensitivity of weight-for-age $>$ 95th percentile in identifying obesity relative to BMI standards is lower in this study than previously reported. A study by Stettler et al demonstrated a sensitivity of $82 \%$ in a study that included over 12,000 children aged 2-19 years using data from the 19942004 the National Health and Nutrition Examination Survey in the United States. (Stettler et al., 2007) The latter report was designed to represent the entire American population, while our study was a subset of children with injuries who presented to an emergency department in Canada. One 
factor that may have contributed to the discrepancy in reported sensitivities is the difference in ethnicities between the studies since BMI and body fat in children differs between ethnic groups. (Deurenberg et al., 1998) In Stettler et al, one-third of the study sample was Mexican American while ethnicity data from our emergency departments demonstrate that about one-third are Southeast Asian Canadians and only 8\% from Central/South America. (Boutis K et al., 2013) Further, our study population may have had a different height/weight distribution than that in the Stettler paper. That is, we may have had a higher percentage of children that were shorter and obese with a weightfor-age percentile that did not meet the obesity cut-off. The latter may be relevant in our study since compared to the general population, there is a greater frequency of childhood obesity amongst those who present to emergency departments, (Prendergast et al., 2011) and we may have had on average shorter children given the relatively higher proportion of Southeast Asian participants. Thus, weight-for-age > 95th percentile may have falsely labelled some shorter children as non-obese, thereby compromising the sensitivity of this definition for obesity. Interestingly, despite the relatively low reported sensitivity, differences between BMI-forage and weight-for-age percentiles were relatively small, with 80 percent of children having BMI-for-age and weight-for-age values that were within five percentage points. Further, cross-classification of weight-for-age and BMI percentiles demonstrated that children with a weightfor-age > 95th percentile, almost $94 \%$ of these also had a BMI-for-age > 85th percentile (overweight - obese). Thus, for the majority of children the age-for-weight cut-points produce results that are similar to the BMI-for age cut-points, although these differences still resulted in many children being falsely labeled as non-obese. In this study, the specificity and negative predictive values of weight-for-age $>$ 95th percentile in this population were very high, above 93\%, and comparable to previously reported values. (Stettler et al., 2007) The latter implies that there may be some value in using weight-for-age $>95$ th percentile as a clinical screening tool for obesity in the emergency department. An earlier study out of the United States identified that approximately $30 \%$ of children who present to an urban emergency department are obese, (Prendergast et al., 2011) and the reported prevalence in this study's population was approximately $16 \%$. Thus, the emergency setting may be a significant untapped resource in identifying childhood obesity. If we use weight-for-age $>95$ th percentile as a screening tool, we can identify approximately two thirds of obese children without falsely labelling others as obese. Emergency departments have been shown to be a key component of the health care system by serving as connectors between acute care and preventative/outpatient management.(Prendergast et al., 2011) Thus, timely referral from the emergency department to a pediatrician and/or specialty clinics focusing on childhood obesity may be an important step in the management of this condition, especially if early intervention has any role in reducing longer-term morbidity.(O'Brien SH et al., 2004) Simultaneously, given the high specificity of the weight-for-age > 95th percentile cut-off, we can avoid erroneous stigmatization of this label and potentially unnecessary treatments or interventions.

Specific age categories and sex were not shown to be significant predictors of the accuracy of the weight-for-age $\geq 95$ percentile cut off defining obesity. Although this did not achieve significance, there was a notable trend that weight-forage $>95$ percentile in younger children (aged 2-5 years) had a lower odds (0.61) of accuracy than older (12-17 years) children. There is currently a paucity of literature available to compare our findings to other data and the rationale for this likely requires further study.

\section{Limitations}

Although BMI-for-age is considered a commonly accepted and feasible reference standard to identify pediatric obesity, it may be limited in its accuracy to diagnose obesity since this index does not directly measure body fat percentage. (Freedman 
and Sherry, 2009) However, recently BMI has been shown in the pediatric population to have moderately high sensitivity and positive predictive value, along with a high specificity in identifying children with excess body fatness, (Freedman and Sherry, 2009) and it is also the basis for the development of the BMI-for-age (and sex) cut points from the Centres for Disease Control, World Health Organization and the International Obesity Task Force. We did not collect data on participant ethnicity, and this would have been an important variable to collect to examine its effect on the accuracy of weight-for-age > 95\% percentile definition of obesity compared to BMI-for-age metric. Further, our study population consisted of children who presented to the emergency department with extremity injuries, and the results may not be generalizable to other populations and/or settings.

\section{Conclusions}

Although there may be limited validity in using this weight-for-age cut-off as a definition for obesity in research that includes children with acute injuries, the high specificity may provide some clinical utility in identifying two-thirds of children who are obese while minimizing false labeling of this condition.

\section{Acknowledgements}

We would like to acknowledge the Pediatric Research Academic Initiative at SickKids Emergency (PRAISE). This research would also not have been possible without the superb efforts of the program manager, Johanna Crudden and the participating PRAISE research assistants. Further, we would like to recognized the excellent efforts of the participating research assistants at British Columbia Children's Hospital Emergency Department who were responsible for the recruitment/enrolment of patients at this site.

\section{References}

Backstrom, I. C., Maclennan, P. A., Sawyer, J. R., Creek, A. T., Rue Iii, L. W. \& Gilbert, S. R. (2012a). "Pediatric Obesity and Traumatic Lower-Extremity Long-Bone Fracture Outcomes," Journal of Trauma and Acute Care Surgery, 73, 966-71.

Backstrom, I. C., Maclennan, P. A., Sawyer, J. R., Creek, A. T., Rue, L. W., 3rd \& Gilbert, S. R. (2012b). "Pediatric Obesity and Traumatic Lower-Extremity Long-Bone Fracture Outcomes," Journal of Trauma and Acute Care Surgery, 73, 966-71.

Boutis, K., Cogollo, W., Fischer, J., Freedman, S. F., Bendavid, G. \& Thomas (2013). "Parental Knowledge of Potential Cancer Risks from Exposure to Computed Tomography," Pediatrics, 132, 305-11.

Campbell, J., Alqhatani, A., Mcrae, L., Kissoon, N. \& Doan, Q. (2013). "Body Mass Index and the Odds of Acute Injury in Children," Pediatric Emergency Care, 29, 21-5.

Daniels, S. R. (2006). "The Consequences of Childhood Overweight and Obesity," The Future of Children, 16, 47-67.

De Onis, M., Blossner, M. \& Borghi, E. (2010). "Global Prevalence and Trends of Overweight and Obesity among Preschool Children," American Journal of Clinical Nutrition, 92, 1257-64.

Deurenberg, P., Yap, M. \& Van Staveren, W. A. (1998). "Body Mass Index and Percent Body Fat: A Meta Analysis among Different Ethnic Groups," International Journal of Obesity \& Related Metabolic Disorders, 22, 1164-71.

Estabrooks, P. A. \& Shetterly, S. (2007). "The Prevalence and Health Care Use of Overweight Children in an Integrated Health Care System," Archives of Pediatrics \& Adolescent Medicine, 161, 222-7.

Formiguera, X. \& Canton, A. (2004). "Obesity: Epidemiology and Clinical Aspects," Best Practice \& Research. Clinical Gastroenterology, 18, 1125-46.

Freedman, D. S. \& Sherry, B. (2009). "The Validity of Bmi as an Indicator of Body 
Fatness and Risk Among Children," Pediatrics, 124 Suppl 1, S23-34.

Kuczmarski, R. J., Ogden, C. l. \& Guo, S. S. (2002). "2000 Cdc Growth Charts for the United States: Methods and Development," Vital and Health Statistics, 11, 1-190.

Leet, A. I., Pichard, C. P. \& Ain, M. C. (2005a). "Surgical Treatment of Femoral Fractures in Obese Children: Does Excessive Body Weight Increase the Rate of Complications?," The Journal of Bone and Joint Surgery, 87, 2609-2613.

Leet, A. I., Pichard, C. P. \& Ain, M. C. (2005b). "Surgical Treatment of Femoral Fractures in Obese Children: Does Excessive Body Weight Increase the Rate of Complications?," The Journal of Bone and Joint Surgery, 87, 2609-13.

O'brien, S. H., Holubkov, R. \& Reis, E. C. (2004). "Identification, Evaluation, and Management of Obesity in an Academic Primary Care Center," Pediatrics, 114, E154-9.

Ogden, C. L. \& Flegal, K. M. (2010). "Changes in Terminology for Childhood Overweight and Obesity," National Health Statistics Reports, 25, 1-5.

Ogden, C. L., Carroll, M. D., Kit, B. K. \& Flegal, K. M. (2012). "Prevalence of Obesity and Trends in Body Mass Index among Us Children and Adolescents, 1999-2010," The Journal of the American Medical Association, 307, 483-490.

Pomerantz, W. J., Timm, N. L. \& Gittelman, M. A. (2010a). "Injury Patterns in Obese versus Nonobese Children Presenting to a Pediatric Emergency Department," Pediatrics, 125, 681-685.
Pomerantz, W. J., Timm, N. L. \& Gittelman, M. A. (2010b). "Injury Patterns in Obese versus Nonobese Children Presenting to a Pediatric Emergency Department," Pediatrics, 125, 681-5.

Prendergast, H. M., Close, M., Jones, B., Furtado, N., Bunney, E. B., Mackey, M., Marquez, D. \& Edison, M. (2011). "On the Frontline: Pediatric Obesity in the Emergency Department," Journal of the National Medical Association, 103, 922-5.

Roberts, K. C., Shields, M., De Groh, M., Aziz, A. \& Gilbert, J. A. (2012). "Overweight and Obesity in Children and Adolescents: Results from the 2009 to 2011 Canadian Health Measures Survey," Health Reports, $23,37-41$.

Ryan, L. M., Teach, S. J., Searcy, K., Singer, S. A., Wood, R., Wright, J. L. \& Chamberlain, J. M. (2010). "Epidemiology of Pediatric Forearm Fractures in Washington," Journal of Trauma-Injury Infection \& Critical Care, 69, S200-5.

Stettler, N., Zomorrodi, A. \& Posner, J. C. (2007). "Predictive Value of Weight-ForAge to Identify Overweight Children," Obesity (Silver Spring), 15, 3106-12.

Tremblay, M. S. \& Willms, J. D. (2000). "Secular Trends in the Body Mass Index of Canadian Children," CMAJ, 163, 1429-33.

Whitaker, R. C. \& Orzol, S. M. (2006). "Obesity among Us Urban Preschool Children: Relationships to Race, Ethnicity, and Socioeconomic Status," Archives of Pediatrics \& Adolescent Medicine, 160, 57884. 